0000 0000 0000 0000 0000 0000 0000 0000 0000 000 0000 000 0000 000 Prosiding

\section{International Conference on Indonesia Culture}

Connectivity and Sustainability :

Fostering Cultural Commons in Indonesia$$
\text { re }
$$ 


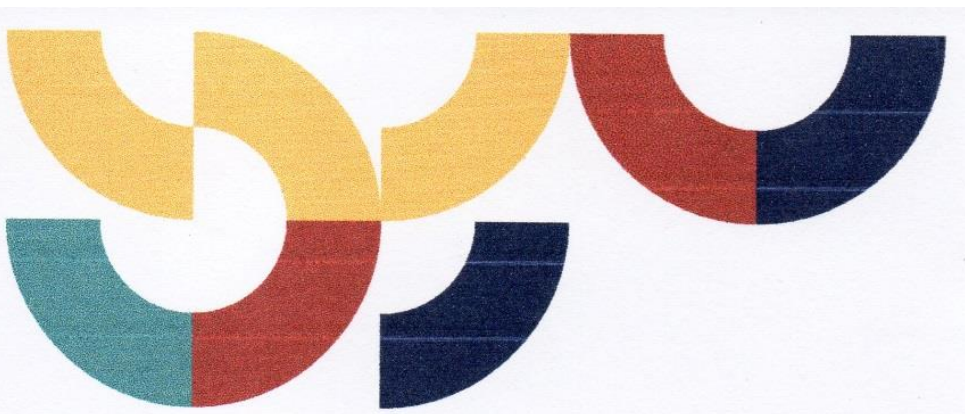

\section{KATA PENGANTAR}

International Conference On Indonesia Culture (ICONIC) merupakan platform gotong royong lintas disiplin melibatkan para peneliti di dalam dan luar negeri yang dirancang untuk memperkaya kajian budaya Indonesia. Tujuannya adalah penyebarluasan hasil riset ke masyarakat dan pemangku kepentingan, sehingga dapat mendorong pelestarian budaya di tingkat masyarakat.

ICONIC 2020 mengusung tema Connectivity and Sustainability: Fostering Cultural Commons in Indonesia. Tema ini kemudian diturunkan ke dalam delapan sub tema yang bertujuan untuk pengembangan ilmu pengetahuan budaya di Indonesia, antara lain: Digital Society and Culture, Politics of Ecology; Jalur Rempah and the Trajectory of Memories; Arts and Activism; Creative Economy and Intellectual Property; Translocation, Transformation, and Transmission of Tradition; Urban Rural Dynamics; dan Diversity of Culture.

Konferensi ini diikuti oleh akademisi, praktisi, dan peneliti dari berbagai bidang ilmu dari seluruh Indonesia dạn luar negeri, yang membahas berbagai bidang kajian dalam bidang kebudayaan Indonesia. Makalah dari Plenary Speakers dan Panel Presenter yang telah dipresentasikan dalam konferensi ICONIC 2020 terangkum dalam prosiding ini. Semoga prosiding ini dapat bermanfaat bagi pengembangan ilmu pengetahuan khususnya kebudayaan di Indonesia.

Akhir kata, kami mengucapkan terima kasih kepada Dekan Fakultas Ilmu Pengetahuan Budaya Universitas Indonesia yang telah mendukung penuh agar konferensi ini dapat terlaksana dengan baik dan kepada seluruh Plenary Speakers, Panel Presenters, Asosiasi Profesi, serta para peserta yang telah berpartisipasi dalam konferensi ini.

Jakarta, Desember 2020

Redaksi ICONIC 


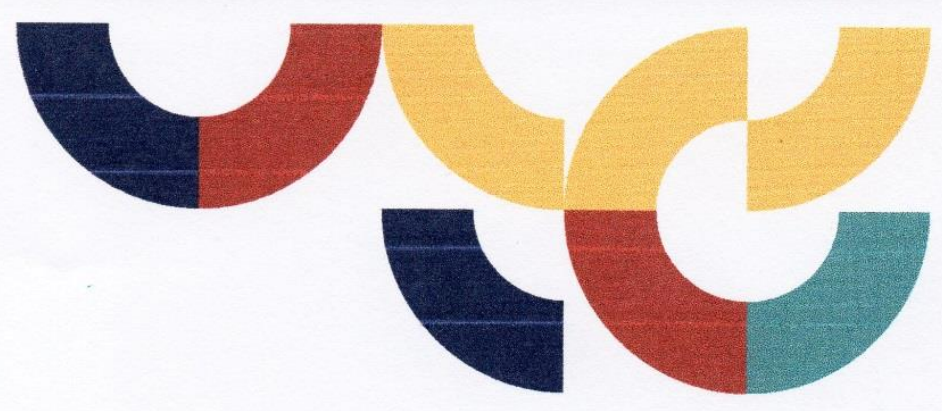

\section{DEWAN REDAKSI}

\section{Pengarah}

Penanggung Jawab

Editor

Tim Penyusun

Perwajahan

Cetakan Pertama

Diterbitkan oleh

\author{
Hilmar Farid \\ Adrianus Laurens Gerung Waworuntu \\ Melani Budianta \\ Manneke Budiman \\ Judi Wahjudin
}

Wawan Yogaswara

Shuri Mariasih Gietty Tambunan

St. Prabawa Dwi Putranto

Zakiyah Egar Imani

Hana Nabilah

Agung

2020

ISSN 2747-1802

Direktorat Pembinaan Tenaga dan Lembaga Kebudayaan

Direktorat Jenderal Kebudayaan

Kementerian Pendidikan dan Kebudayaan

Sanksi Pelanggaran Pasal 72:

Undang-Undang Nomor 19 Tahun 2002 Tentang Hak Cipta

Barangsiapa dengan sengaja dan tanpa hak melakukan perhuatan sehagaimana dimaksud dalam Pasal 2 ayat (1) atau Pasal 49 ayat (1) dan ayat (2) dipidana dengan penjara masing-masing paling singkat 1 (satu) bulan dan/atau denda paling sedikit Rp 1.000.000,00 (satu juta rupiah), atau pidana penjara paling lama 7 (tujuh) tahun dan/atau denda paling banyak Rp 5.000.000.000,00 (lima miliar rupiah).

Barangsiapa dengan sengaja menyiarkan, memamerkan, mengedarkan, atau menjual kepada umum suatu Ciptaan atau barang hasil pelanggaran I lak Cipta atau Ilak Terkait scbagaimana dimaksud pada ayat (1) dipidana dengan pidana penjara paling lama 5 (lima) tahun dan/atau denda paling banyak Rp 500.000.000,00 (lima ratus juta rupiah). 


\section{DAFTAR ISI}

Kata Pengantar

Dewan Redaksi

Daftar Isi

\section{PLENARY SPEAKERS}

Menyoal Konstruksi Sosial Tentang Alam dalam Logika Kapitalism sebagai

Akar Penyebab Krisis Ekologi di Indonesia: Apakah ada peluang untuk perubahan?

Suraya A Afiff

Art as Interdisciplinary Intervention, or Can Artists, Activists, Academics Collaborate?

Ari J. Adipurwawidjana

Antara Kota dan Desa

Abidin Kusno

North Sumatra as a Melting Pot of Cultural Diversity (Mid-Ninth - Fourteenth Centuries CE)

Daniel Perret .........

Hak Kekayaan Intelektual : Ekspresi Budaya Tradisional dan Karya Seni

Dr. Inda Citraninda Noerhadi

\section{PANEL PRESENTER}

Identitas Budaya Orang Enggano di Pulau Enggano: Kompromi Budaya Lokal dan Pendatang

Rois Leonard Arios

Parents' Challenges in Distance Learning during the COVID-19 Pandemic in Senganten Village

Luly Prastuty

Antara Kuasa Negara dan Warisan Jalur Rempah: Perdagangan Beras di Sulawesi Selatan Pada

Dekade 1930-an

Syafaat Rahman Musyaqqat

Industri Teh Poci : Pelestarian Olahan Teh Dan Dampaknya Terhadap Masyarakat Slawi

Tahun 1998-2004

Arfan Habibi

Di Balik Lensa Proklamasi Kemerdekaan Indonesia

Archangela Yudi Aprianingrum

Penguatan Pengetahuan Lokal Masyarakat dalam Kebencanaan Melalui Pengarsipan Digital

Ainar Tri Asita, S.Sos

Kemas Ulang Informasi Cerita Gareng Petruk Menjadi Gim Permainan Peran

Dr. Ike Iswary Lawanda, M.Si.

Transformation The Meaning of Nyadran Tradition for Contemporary Society

Bariq Maulana 
Transforming Digital Society In Forming Trust and Intimate Relationship

Ichmi Yani Arinda Rohmah, S.Pd., M.Sosio, Dr. Andi Achdian, M.Si

Strategi Transmisi Kearifan Lokal melalui Tradisi Tutur (Studi Kasus Gerakan \#KawanDongengDaring)

Khaolil Mudlaafar, Istighotsatul Khoiriyah, Yukrimah Nur Rohhim

Ritual Adat Ulur-Ulur: Its Transformation and Survival

Luqman Hakim

Memetakan Seni dan Budaya adalah Kunci Kebertahanan Identitas Indonesia dimata Dunia

Armansyah Maulana Harahap

Upacara Garebeg Keraton Yogyakarta di Masa Pandemi Covid-19

Pandji Saputra, S.Pd

Art as Interdisciplinary Intervention, or Can Artists, Activists, Academics Collaborate?

Ari J. Adipurwawidjana

Budaya Material yang Berkembang dan Mempengaruhi Industri Perabot di Indonesia

Andrea Natasha, Aditya Yuliantina Dewi, Alam Dava Arakananta, Aldi Adrian Yusyahrisal, Alvin Leonard Bumulo, Andien Lufh Islah Maulinda Rabini Achmad, Annisa Fredlina Yudhistira, Ariella Alandra Lomantojo,

Ayyas Naufal, Cintya Aprilia Dewi

Tradisi Keboan Aliyan di Dusun Sukodono : Dari Ritual ke Festival

Linda Astri Dwi Wulandari

Jejak Jalur Rempah dalam Penamaan Nama Tempat di Kawasan Banten Lama:

Tinjauan Sejarah dan Toponimi

Tubagus Umar Syarif Hadi Wibowo, M.Pd

Ngindung Ka Waktu, Ngawula Ka Zaman. Bagaimana Orang Sunda Modern Menafsir Zaman dan

Relevansinya Atas Kehidupan Melalui Kalender Caka-Sunda

Mardiansyah Nugraha, S.Pd, M.A, Dr. Gunawan Undang, M.Si

Musik dan Budaya Kosmopolitan: Merapal Pergerakan Skena Indie di Indonesia Tahun 2000-2008

Ilham Nur Utomo

Representation of Nationalism in Love and Future Goal: A Semiotic Analysis of John Fiske in the

Film of Habibie \& Ainun 3

Ardiansyah Bagus Suryanto

Setigi dan Wagos: Dinamika Alam dan Sosial Gresik Utara dalam Perspektif Ekofenomenologi

Lailatus Sholihah, Levi Nur Cahyani

Jalur Rempah dan Model Difusi Pengetahuan

Irawan Santoso Suryo Basuk

Transmission of Traditional Medicine Knowledge in Sebesi Island Community, South Lampung

Vera Budi Lestari Sihotang

Paheman Radya Pustaka : Suatu Cerminan Pemajuan Kebudayaan ?

Efel Indhurian

Nasi Grombyang: Makanan Khas Pemalang dalam Rekam Zaman

Neilia Kamal, Ilham Nur Utomo

Diversity in Aceh: The implementation of the local wisdom tradition by the term of

'Keurija Udép and Keurija Matèè' in Latong Village, Nagan Raya

Safira Mustaqilla 


\title{
Jejak Jalur Rempah Dalam Penamaan Nama Tempat Di Kawasan Banten Lama: Tinjauan Sejarah Dan Toponimi
}

\author{
Tubagus Umar Syarif Hadi Wibowo \\ Jurusan Pendidikan Sejarah, FKIP, UNTIRTA \\ umarhadiwibow90@untirta.ac.id
}

Kawasan Banten Lama sepanjang Abad ke-16 merupakan pusat Kesultanan Banten yang mengalami kemajuan pesat dalam perniagaan sekaligus menjadi salah satu pusat jalur rempah dengan komoditi utama perdagangan ketika itu lada. Perannya sebagai kawasan jalur rempah sebagai titik penghubung (connecting point) dan titik perjumpaan (meeting point) antara masyarakat setempat (hinterland) dengan dunia luar (foreland). Konektivitas di sekitar jalur rempah itu membawa dampak pada akulturasi budaya masyarakat Banten yang majemuk. Salah satu dampaknya adalah Sejarah Penamaan nama tempat di Kawasan Banten Lama yang tidak dapat dilepaskan dari pengaruh aktivitas perdagangan jalur Rempah. Sejarah penamaan nama tempat (toponimi) tidak dapat dilepaskan dari keberadaan kawasan Banten Lama pada abad ke-16 sebagai pusat jalur rempah yang memberikan jejak yang cukup signifikan pada keberadaan nama tempat di Kawasan Banten Lama pada masa kini, seperti "Kampung Pamarican" yang berasal dari kata merica atau lada. Tulisan ini merupakan penelitian sejarah dan toponimi yang bertujuan mendapatkan fakta sejarah penamaan nama tempat yang memiliki keterkaitan dengan jejak jalur rempah di Kawasan Banten Lama. Metode yang digunakan adalah metode kualitatif dengan sumber data yang ditemukan dari studi literatur dan studi lapangan. Hasil temuan penelitian menunjukkan bahwa penamaan nama tempat yang dipengaruhi oleh jejak Jalur Rempah di Kawasan Banten Lama dapat terbagi dalam tiga kategori yaitu toponimi berdasarkan komunitas etnis yang bermukim, toponimi berdasarkan kegiatan perdagangan, dan toponimi berdasarkan elite perdagangan. Sebagian nama-nama tempat tersebut masih digunakan hingga kini bahkan beberapa masyarakat dari etnis luar Banten yang bermukim masih mewariskan tradisi leluhurnya.

Kata Kunci: Jalur Rempah, Toponimi, Kawasan Banten Lama, Nama

\section{PENDAHULUAN}

Jalur rempah, juga dikenal sebagai Jalan Sutra Maritim, adalah nama yang diberikan untuk jaringan rute laut yang menghubungkan Timur dengan Barat, membentang dari pantai barat Jepang, melalui pulau-pulau di Indonesia, di sekitar India sampai ke daratan Timur Tengah - dan dari sana, melintasi Mediterania ke Eropa. Jaraknya lebih dari 15.000 kilometer dan, bahkan hari ini, bukanlah perjalanan yang mudah. Perjalanan ini tidak dilakukan semata-mata dalam semangat petualangan, di belakangnya ada kekuatan pendorong utama yaitu perdagangan (https://en.unesco.org/).

Dalam jalur rempah, pola perdagangan dibentuk oleh pedagang yang membeli dan menjual barang dari pelabuhan ke pelabuhan. Barang utama dan paling menguntungkan yang diperdagangkan adalah rempahrempah. Orang mungkin menganggapnya hanya sebagai penyedap makanan. Namun, kata "rempah-rempah" berasal dari bahasa Latin species, yang berarti "barang yang memiliki nilai khusus", dibandingkan dengan barang perdagangan biasa (https://en.unesco.org/).

Tapi species atau barang berharga bukanlah satu-satunya titik pertukaran antara para pedagang. Mungkin yang lebih penting adalah pertukaran pengetahuan: pengetahuan tentang masyarakat baru dan agama mereka, bahasa, keahlian, keterampilan artistik dan ilmiah. Pengetahuan segar yang terbawa melintasi lautan dari pelabuhan ke pelabuhan lainnya. Jalur rempah saat ini tidak cukup hanya dimaknai sebagai jalur perdagangan dimana terjadi proses ekonomis rempah, jalur rempah dimaknai sebagi konsepsi identitas bangsa Indonesia yang memiliki ikatan sejarah dengan kerajaan ataupun kesultanan yang pernah berjaya di masanya.

Secara khusus, Banten menjadi salah satu mata rantai yang membentuk identitas jalur rempah di nusantara. Dari sinilah rempah-rempah bercita rasa pedas menjadi komoditas utama perdagangan, lada. Lada yang diperdagangkan tidak hanya berasal dari Banten (pegunungan) daerah jajahannya (Lampung, Landak, dan Sukadana), melainkan juga dari daerah lain seperti, misalnya, Aceh, Palembang, Cirebon, Priangan, Jepara, dan dari daerah lainnya (Sudarno, 2008:29).

Lewat perdagangan utama Karangantu, menjadikan Banten sebagai titik penghubung (connecting point) dan titik perjumpaan (meeting point) antara masyarakat setempat (hinterland) dengan dunia luar (foreland). Bagi 
kerajaan-kerajaan maritim Indonesia, pelabuhan merupakan pintu gerbang (bahasa Latin: portus) bahan-bahan ekspor dan impor. disini arus impor dan ekspor dapat diawasi dan dikenakan bea seperlunya. Oleh sebab itu, pelabuhan merupakan sumber penghasilan yang amat penting bagi kerajaan (Marwati Djoened Poesponegoro \& Nugroho Notosusanto, 2008:153)

Identitas pelabuhan sebagai pintu gerbang bagi kegiatan ekonomi merupakan pendorong bagi masyarakat pesisir untuk menggantungkan mata pencaharian dari perdagangan dan pelayaaran. Kekuatan dari luar Banten dalam perdagangan sangat memegang peranan penting dan memiliki ciri khas kosmopolitan. Karakter terbuka negara Banten ini diakui oleh Van Leur (1983), yang berbicara dalam istilah Weberian tentang 'kerajaan pelabuhan' atau Bluss memperkenalkan konsep Polanyian tentang 'pelabuhan perdagangan' ke dalam historiografi Banten (J. Talens, 1993:333-355)

Tidak ketinggalan pedagang dari kepulauan di Nusantara sangat besar peranannya, terutama dalam arus timbal balik hasil-hasil produksi daerah masing-masing. Hal itu memungkinkan adanya mobilitas horizontal di kalangan pedagang dalam negeri, karena perpindahan dari satu kota ke kota lain untuk mencari keuntungan. Pedagang-pedagang dalam negeri dari nusantara yang berdatangan di Banten misalnya dari Melayu, Banda (Maluku), Banjar, Bugis-Makassar dan Malaka. Mereka membentuk kelompok-kelompok etnis yang memiliki pemukiman tersendiri di Kesultanan Banten. Bahasa Melayu digunakan antara pedagang dalam negeri sebagai bahasa pengantar (lingua franca) dalam berinteraksi dan berkomunikasi di wilayah Kesultanan Banten.

Rekonstruksi sejarah jalur rempah di Banten pada masa kesultanan dapat ditelusuri dari beberapa aspek yang menjadi warisan budaya, yaitu: Ekonomi, Politik, Agama, Budaya, Klaster/ toponimi, Pengetahuan dan Teknologi Tradisional (Helmy Faizi Bahrul Ulumi, 2020). Aspek toponimi menjadi unik dan menarik untuk dijadikan pisau bedah dalam menggali melacak pertanyaan sejarah seputar jalur rempah. Dengan pendekatan toponimi juga dapat ditelusur adanya interaksi antara kebudayaan dari berbagai bangsa pada masa lalu yang mempengaruhi toponimi kawasan Banten Lama. Sekaligus dengan pendekatan toponimi dapat digunakan untuk melestarikan budaya masa lalu nenek moyang kita (intangible cultural heritage) sampai saat ini.

Metode yang digunakan adalah metode kualitatif dengan sumber data yang ditemukan dari studi literatur dan studi lapangan. Penamaan tempat di Kawasan Banten Lama yang diungkap dalam pembahasan ini berkaitan dengan nama pemukiman yang keberadaannya telah ada pada masa Kesultanan Banten, hal itu dibuktikan dari sumber-sumber seperti peta Eropa dan beserta laporan dari orang Eropa, Sajarah Banten, tradisi tutur masyarakat lokal, dan sumber literatur lain yang berhubungan dengan topik penelitian.

\section{TOPONIMI BERDASARKAN KOMUNITAS ETNIS}

Toponimi atau penamaan nama tempat di kawasan Banten Lama berdasarkan komunitas etnis merupakan realitas historis dari beragamnya penduduk di kawasan Banten Lama dilihat dari latarbelakang ras dan suku. Penduduk ini berasal dari luar dan dalam Nusantara. Mayoritas adalah pedagang yang diberikan kesempatan dari pihak kesultanan untuk bermukim di wilayah pusat ibukota Banten. Kebanyakan penduduk kota termasuk golongan pedagang. Sebagain besar golongan pedagang tersebut berasal dari luar Kesultanan Banten. Orangorang asing tinggal di kampung-kampung di luar dinding keraton (extra muros), mengelompok seperti suku (Yulianto Sumalyo, 2006:496). Di kota mereka punya perkampungan tersendiri. Bagi pedagang asing yang ingin menetap, harus memperoleh izin dari penguasa kerajaan terlebih dahulu. Berdasarkan penelusuran dari sumber peta-peta lama wilayah Banten Lama yang dibuat oleh orang-orang Eropa dan sumber literatur sejarah, toponim atau tempat berlatarbelakang komunitas etnis yang turut andil dalam perdagangan jalur rempah di Banten, yaitu:

\section{- Pecinan}

Kampung Pecinan berada di sebelah Barat Masjid Agung Banten. Nama kampung Pecinan berkaitan dengan keberadaan etnis Tionghoa di Kesultanan Banten. Di wilayah tempat tinggal mereka, Pacinan, yang terletak di bagian barat kota, terlihat rumah-rumah Banten terbagus. Terletak di samping pelabuhan, tempat itu juga memiliki toleransi di mana orang-orang asing, terutama orang Eropa, merasa betah karena menemukan tempat berlindung dan sekaligus juga hiburan. Di Pecinan inilah rumah orang-orang Inggris dan Belanda berada. Rumah mereka jauh lebih besar dan tinggi dibandingkan dengan rumah pada umumnya (James R. Rush, 10).

Pedagang Cina di Kesultanan Banten merupakan golongan mayoritas di antara pedagang-pedagang asing lainnya. Mereka mempunyai pasar di bagian Kesultanan Banten, yaitu di tengah-tengah perkampungan Pecinan. Pedagang Cina sangat berperan dalam menjembatani para petani lada di Banten 
dengan para pembeli dari Eropa. Pedagang Cina bahkan sampai ke pedalaman (Gunung Pulosari) untuk menampung hasil lada dari petani.

Valentijn (1858) mengatakan peranan pedagang Cina di Banten adalah sangat penting. Bila kapal-kapal Cina belum datang maka pasar-pasar di Banten Sepi. Mereka membawa barang dagangan berupa: porselin, sutra, laken (kain tenun dari bulu domba;, kain wol), kain beludru, benang emas, air raksa, kertas aneka warna, almanak, cermin emas, ssir kipas, payung, belerang, dan lain-lain.

Pada masa wali kerajaan, Pangeran Aria Rana Menggala, orang Tionghoa berjumlah banyak dan hidup makmur di Banten. Mereka menduduki tempat penting dalam kehidupan kota, dan memegang peranan yang diakui secara resmi dalam bidang ekonomi dan politik. Misalnya selama paro kedua abad 17, yang dipilih menjadi syahbandar (kepala pelabuhan) Banten hampir semuanya Tionghoa, yang sangat berpengaruh dalam perdagangan antar pulau, disebabkan oleh besarnya hubungan dagang dengan jungjung (kapal layar) yang datang dari Tiongkok.

Syahbandar yang terkenal saat itu adalah seorang syahbandar Tionghoa gundul, bernama Kiyai Ngabehi Kaystsu. Meski sudah masuk Islam, Kaytsu tidak mengganti namanya. Tapi memakai gelar Kiyai (guru) Ngabehi-administrator dibawah adipati) Kaytsu. Pada taun 1661, Kaytsu meninggalkan jejak pada topografi perkotaan. Sumber-sumber sejarah mencatat bahwa ia membangun rumah batu di wilayah Pacinan, dekat loji Inggris, yang dikunjungi oleh Sultan sendiri, diiringi para pejabat Istana.

\section{- Pakojan}

Sebutan "Pakojan" (khojah) berasal dari bahasa Parsi/Persia (sekarang Iran). Kojah atau Khojah, dari Persia chojah atau Khwaja, sebuah sebutan yang sama dengan gelar "Sir" di Inggris mulia. Di Turki, di mana ia diucapkan Khoja, ia diperuntukkan untuk juru tulis atau seseorang yang memakai turban (kain penutup kepala). Di India, sebutan khoja mengacu pada kaum Ismalilites, para pengikut Aga Khan (J.C. Van Leur, 1960:239). Di Kepulauan Indonesia, Kampung Pekojan diperuntukkan pedagang muslim yang datang dari Arab, Persia, India, Tamil, Gujarat, Mesir, Goa, dan lain-lain. Kampung Pakojan masih ditemukan dengan topo-nya (ilmu nama-nama tempat) dan juga dengan tempat-tempat nyata di sejumlah kota-kota sejarah seperti Banten, Jakarta, dan lainnya (Uka Tjandrasasmita, 2009:22). Di kampung Pakojan Banten sekarang ini masih terdapat jejak peninggalan berupa bekas masjid Koja, letaknya di selatan jalan yang menghubungkan Karangantu dan benteng Speelwijk, sekarang hanya tinggal reruntuhannya. Nama "kojah" juga disebutkan dalam Sajarah Banten, pupuh XXXIV, yaitu ketika utusan Sultan Abulmafakhir Mahmud Abdulkadir menghadap ke penguasa Mekkah.

\section{- Kebalen}

Kampung Kebalen berada di sebelah selatan Keraton Surosowan. Kata Kebalen berasal dari kata Bali dengan awalan "ke" dan akhiran "an". Di Kesultanan Banten, kata "Kebalen" adalah sebutan dari pemukiman orang Bali. Adapun akhiran "an" menunjukkan kata tempat, yang artinya tempat tinggal. Jadi, Kebalen berarti tempat tinggal orang Bali di Kesultanan Banten.

\section{- Karoya}

Karoya ataupun Kroya berasal dari kata Koga. Kata tersebut adalah nama sebuah pemukiman orang Koga, dari India, yang terletak di sebelah tenggara Keraton Surosowan. Orang-orang asing, seperti India, mempunyai peran tersendiri di Kesultanan Banten. Hal ini dibuktikan oleh Syahbandar Banten (1604) yang berasal dari tanah Keling. Sumber Belanda mengatakan bahwa laksamana pun berasal dari negeri Keling (India).

Sepanjang abad ke-16 dan 17 di Banten hanya ada satu pejabat yang melayani para nakhoda dan pedagang dari semua bangsa. salah seorang tokoh yang paling khas dari Tamil, yang ditemui orang Belanda pada tahun 1596 yang menjulukinya "Guillin Panjan (Keling Panjang) dari India dan Tamil. Kekuatan ekonomi bangsa Keling dan pedagang India (Gujarat dan Benggala) di kota itu sampai tahun 1605, yaitu sampai mereka diusir, setelah kekalahan partai yang mereka dukung dalam pertikaian politik dalam negeri. 


\section{- Kampung Bugis}

Kampung Bugis adalah tempat tinggal orang-orang Bugis yang letaknya di dekat Pelabuhan Karangantu. Selain itu, Kesultanan Banten telah menjalin persahabatan yang sangat erat dengan Kesultanan di Sulawesi, yaitu Kesultanan Makassar. Salah satu wujudnya yaitu Sultan Ageng Tirtayasa memanggil Syekh Yusuf Al-Makkassari untuk menjadi Mufti Agung, guru dan menantu Sultan.Syekh Yusuf merupakan guru sekaligus pemimpin tarekat Khalwatiah saat itu. Beliau juga berjasa dalam membantu Sultan Ageng dalam melawan VOC (1651-1683).

Keberadaan Kampung Bugis masih tampak hingga kini. Namanya sekarang adalah Kampung Bugis Baru. Selain itu, ciri khas yang masih terus dijaga oleh masyarakat Bugis di kampung ini yaitu beberapa rumah panggung dari bahan kayu yang masih tegak berdiri. Biasanya di kolong rumah panggung tersebut terdapat ruang untuk menyimpan barang dan hewan peliharaan. Sebagian dari mereka masih memakai kayu bakar untuk memasaknya. Kayu bakarnya itu diambil dari hutan bakau yang ada di pesisir Teluk Banten

\section{TOPONIM BERDASARKAN KEGIATAN PERDAGANGAN}

Jejak penamaan nama tempat yang berhubungan dengan jalur rempah adalah tempat-tempat yang memiliki asal-usul dari kegiatan perdagangan, baik itu berupa barang atau komoditi perdagangan, fasilitas ataupun infrastruktur di Kesultanan Banten dimana terjadinya transaksi ekonomi, seperti pasar dan pelabuhan. Toponim berdasarkan kegiatan perdagangan dapat disimak di bawah ini:

\section{- Pabean}

Pabean yaitu tempat untuk menarik pajak di pelabuhan. Kata Pabean berasal dari kata "bea" dengan awalan " $p a$ " dan akhiran " $a n$ ". Bea sendiri berarti pajak atau cukai. Tempat ini terletak di sebelah barat laut Keraton Surosowan. Jan Jansz Karrel, tanggal 6 Agustus 1596 mencatat bahwa kapal-kapal asing yang hendak berlabuh di Banten dari pelabuhan terlebih dahulu harus melalui tolhuis atau tempat pungut pajak. Tempat itu oleh orang Belanda disebut De Baviaan, yaitu sebuah bangunan bulat milik orang-orang Banten yang terletak di seberang Ci Banten dekat Van de Boom (dalam bahasa Indonesia berarti "pohon"). Bangunan ini disebut Pabean oleh orang-orang Banten, kemungkinan besar bangunan in adalah tempat orang membayar bea jika hendak masuk ke Banten, selanjutnya orang-orang Belanda menyebutnya Baviaan, suatu bunyi yang kedengerannya mirip dengan Pabean (dalam Sajarah Banten pupuh LI, disebut Pabeyan) .

Petugas yang bertanggung jawab mengatur pajak dinamakan Syahbandar. Di Pabean (dalam sumber lain ditulis: Fabyam) berlangsung acara penimbangan dan penilaian barang-barang dagangan, serta penetapan jumlah bea yang harus dibayar. Di situlah biasanya berkantor syahbandar, yang juga bertanggung jawab atas pabean. Sebelum zaman kesultanan, syahbandar sudah lama diketahui keberadaannya. Pada bulan Agustus 1522, utusan Portugis Henrique Leme, yang dikirim untuk merundingkan perjanjian dagang dengan "Kerajaan Sunda" (yang tak lain adalah kerajaan Banten Girang) menyebutkan bahwa di antara lawan bicaranya ada Bengar Xabendar da Terra (yaitu Bengar, syahbandar negeri itu).

Pajak merupakan salah satu sumber pendapatan bagi kas kesultanan Banten, setiap kapal yang akan berdagang di wilayahnya diwajibkan memiliki surat pas yang bersegel dari Sultan. tanpa surta pas ini, kapal-kapal tersebut tidak akan diijinkan berdagang. Sanksi pelanggaran tersebut adalah pengusiran dan/atau penyitaan kapal. Bilamana kapal-kapal yang membali lada, diketahui tidak memiliki pas masuk, maka kehadirannya di wilayah Banten akan ditolak. Apabila mereka bersikeras maka kapal dan uang mereka akan disita oleh Sultan. Seluruh awaknya akan dibawa ke Surosowan.

\section{- Pelabuhan Karangantu}

Pelabuhan Karangantu merupakan pelabuhan utama bagi pintu masuk para pedagang asing. Barangbarang dari luar yang merupakan komoditas ekspor, seperti keramik, gerabah, gading gajah, beras dan rempah-rempah banyak diperdagangkan di pasar dekat Pelabuhan Karangantu. Lada menjadi komoditas ekspor utama bagi perdagangan di Kesultanan Banten. Berita Portugis menyebutkan peranan Kesultanan 
Banten sebagai pelabuhan lada, kedudukannya menempati urutan kedua setelah Sunda Kelapa (A.Daliman, 2012:147).

Karangantu memainkan peran penting sebagai pelabuhan utama dan pasar yang difungsikan sebagai pelabuhan dagang bagi lingkup lokal maupun internasional. Di Karangantu sebagai pelabuhan Banten, digambarkan sebagai berikut: pedagang-pedagang dari Cina membawa uang kepeng yaitu uang yang terbuat dari timah, porselen, kain sutra, beludru benang emas, kain sulaman, jarum sisir, payung, selop (sepatu), kipas, kertas, dan sebagainya (Tb. Hafidz Rafiuddin, 6).

Kapal-kapal asing, seperti dari Persia, India, Cina, Asia Tenggara, dan Eropa yang berlabuh di Pelabuhan Karangantu harus mendapat izin dari syahbandar $($ syah $=$ raja, bandar $=$ pelabuhan, raja/ketua pelabuhan) (Mundardjito (Ed.), 2005:125). Menurut catatan Jan Jansz Kaeral (1596) disebutkan bahwa kapal-kapal asing yang berlabuh di Pelabuhan Banten harus mendapat izin syahbandar. Kapal-kapal yang berlabuh di bandar Banten meski hanya singgah sementara ditarik berupa pajak parkir, yang disebut pajak ruba-ruba.

Tugas utama seorang syahbandar adalah mengurus dan mengawasi perdagangan orang-orang yang dibawahinya, termasuk pengawasan di pasar dan gudang. Ia harus mengawasi timbangan, ukuran dagangan, dan mata uang yang dipertukarkan. Syahbandar diangkat dari kalangan saudagar asing yang punya kekayaan paling besar.

Hal ini dibuktikan oleh Syahbandar Banten (1604) yang berasal dari tanah Keling. Sumber Belanda mengatakan bahwa laksamana pun berasal dari negeri Keling (India). Melalui jabatan syahbandar, orang asing dapat mendapat pengaruh yang besar. Mereka mendapatkan hak prioritas dalam hak berjual beli lada dengan harga murah dan duduk sebagai dewan kerajaan (Marwati Djoened Poesponegoro \& Nugroho Notosusanto, 2008:151).

Pejabat yang mengepalai para syahbandar adalah tumenggung yang berkuasa atas seluruh kota dan pelabuhan. Dalam urusan dagang, kedudukannya sangat penting karena mereka yang menerima bea masuk dan bea ekspor dari barang yang diperdagangkan, dan mengadili perkara-perkara dalam perdagangan.

Pada perkembangan selanjutnya, sekitar abad 17-19, seperti tampak pada peta Serruir, Karangantu tidak lagi ditandai sebagai pasar, tetapi sebagai pelabuhan yang dikelilingi oleh tambak ikan. Kini Karangantu masuk dalam kecamatan Kasemen, Kota Serang, Banten. Mengenai Asal mula nama Pelabuhan Karangantu sendiri, masih misterius. Konon ada sebuah kapal kompeni yang membawa guci berisih rohroh, namun dalam pelayaran kapal tersebut menabrak karang, dan guci itu pecah, dan hantu-hantu itu pun keluar. Ada juga menurut masyarakat setempat, karena banyak hantu-hantu yang bergentayangan di pelabuhan tersebut.

\section{- Pasar}

Sumber Belanda pada abad ke-16, mendeskripsikan bahwa pasar di Banten saat itu ada tiga: pertama, yaitu Pasar Karangantu disebelah timur kota. Pasar ini dibuka pada waktu pagi hingga siang hari, para pedagang yang berdatangan di pasar adalah orang Bugis, Jawa, dan sebagainya, serta orang-orang asing yang terdiri dari orang Portugis, Arab, Turki, Cina, Quillin (Keling), Pegu (Birma), Malaya, Bengal, Gujarat, Malabar, Abesinia. Pasar kedua, adalah pasar yang terletak di Paseban (alun-alun), yang dibuka sepanjang hari (Desril Riva Shanti, 2010:98). Ketiga, Pasar Pecinan yang letaknya ditengah-tengah perkampungan pedagang dari Cina merupakan pasar ketiga di Kesultanan Banten. Lain pasar pusat kota, lain pasar perkampungan. Pasar di perkampungan terselenggara pada hari tertentu dan intensitas perdagangannya pun tidak sampai seharian penuh.

Aktivitas perekonomian Pasar Pecinan di Kesultanan Banten, menurut keterangan sumber Belanda, diselenggarakan sehari sebelum atau sesudah pasar lain dibuka. Jadi, pasar ini buka pada waktu pasar lain tutup (Desril Riva Shanti, 2010:99). Pasarnya sangat ramai. Menurut sumber Belanda, jika tidak ada orang Cina di Banten maka pasar-pasar tersebut akan sepi, karena sebagian besar yang berkuasa dan berdagang adalah orang-orang Cina.

Barang-barang yang didagangkan di pasar terdiri atas produksi dalam negeri dan luar negri. Misalnya saja, orang Cina berdagang kain sutra, beludru, porcelin, peti-peti hias, kertas emas, dan lain-lain. 
Sementara peagang India menjajakan bahan-bahan dari kaca, gading, permata dari Bombay (India), berjenis-jenis tekstil dari Gujarat. Orang-orang Arab menjual bermacam-macam permata dan obat-obatan.

Produksi dalam negeri yang dijual meliputi lada, buah-buahan, sayur-sayuran, gula, madu, gambir, bumbu, bahan untuk atap rumah, keris, tombak dan sebagainya. Selain itu diperdagangkan juga gerabah untuk keperluan rumah tangga. Mata uang utama yan dipergunakan dalam perdagangan ini adalah mata uang Cina yang disebut Cash. Selainitu, dalam peta lawas buatan orang Eropa ada toponim bernama Pasar Anyar, menunjukkan tempat ini merupakan sebuah pasar yang baru (bhs. Jawa=“anyar"). Letaknya sendiri di sebelah timur Keraton Surosowan terletak di sebelah timur Keraton Surosowan.

\section{- Pamarican}

Toponimi "Pamarican" di Banten menunjukkan bahwa lokasi itu merupakan pusat lada atau setidaknya berkaitan dengan lada. Banten sebagai pusat lada telah berlangsung sejak masa Kerajaan Sunda dimana kerajaan Islam belum terbentuk. Keunikan Banten dibandingkan dengan negara-negara pengekspor lada yang lain di dunia melayu, di wilayah yang kecil ini pembeli dengan mudah dapat berhubungan langsung dengan penghasil hari (Desril Riva Shanti, 2010:103).

Keunikan Banten dibandingkan dengan negara-negara pengekspor lada yang lain di dunia melayu, di wilayah yang kecil ini pembeli dengan mudah dapat berhubungan langsung dengan penghasil. Para pedagang Cina di Banten membeli lada secara langsung dari petani. Pada bulan-bulan Februari dan Maret, yaitu pada saat sungai dapat dilayari; para petani membawa lada mereka dengan menggunakan perahu. Orang-orang Cina yang tinggal di Banten mendapat kesempatan lebih dulu untuk membeli lada, tanpa harus meninggalkan tempat tinggal mereka, karena mereka tinggal di alur sungai itu.

Sebelum musim hujan tiba, biasanya pedagang-pedagang Cina pergi ke pedalaman untuk membeli lada. Mereka sangat memahami bahwa kesempatan membeli lada secara langsung dari tangan pertama, akan sangat menguntungkan. Pada saat kapal-kapal dari Cina datang ke Banten, harga lada naik dua kali lipat. Pedagang-pedagang dari Asia Barat juga datang untuk membeli lada dan benda-benda porselin Cina (Rouffaer \& Ijzerman III, 121).

Lada, terutama lada hitam, merupakan rempah-rempah yang menjadi incaran utama bangsa Eropa dalam perdagangan di nusantara. Belanda sangat berhasrat menguasai perdagangan utama di teluk Banten. Untuk itu dibangun benteng Speelwijk di sekitar kampung ini, salah satu tujuannya adalah untuk mengontrol perdagangan lada. Tindakan Belanda yang terus berusaha memonopoli lada ditentang oleh Sultan Banten. Sehingga terjadilah perang antara Belanda (VOC) denga kesultanan Banten yang dipimpin Sultan Ageng Tirtayasa pada tahun 1651-1683.

Kebesaran Banten dengan perdagangan lada-nya telah sirna ditelan zaman. Sekarang tidak terdapat lagi pohon lada di bekas kesultanan Banten. Yang tersisa hanya toponimi atau nama tempat Pamarican di sebelah barat keraton Surosowan, tepatnya di sekitar Jalan Bio Banten sekarang, sebagai tapak tilas bahwa negeri ini pernah terkenal dengan ladanya.

\section{- Toponim Lainnya}

Berdasarkan Peta Serrurier (1900) toponim lainnya yang berkaitan dengan kegiatan perdagangan yaitu: Penjaringan (pemukiman nelayan dan pembuatan jaring ikan, Pakawatan (tempat pembuatan jala ataupun jaring yang lain adalah di Pakawatan), Pasulaman (tempat para pengrajin sulam), Pajatran (tempat kerajinan tenun), Kagongan atau Pagongan (tempat pemain dan pembuat gong dan gamelan), Kemeranggen atau Pamaranggen (tempat pembuatan keris), Pawilahan (tempat pengrajin bambu), Pratok (tempat pengrajin tempurung kelapa atau batok kelapa), Kepandean (tempat penempa besi untuk dibuat alat-alat senjata dan perkakas dari logam), Panjunan (tempat pengrajin gerabah, periuk, tempayan dan belanga), Kamasan (pemukiman para pengrajin asesoris dari logam emas), Sukadiri (pemukiman tukang pengecoran logam dan pembuatan senjata perang), Tambak (tempat yang dijadikan tanggul atau bendung di pinggir laut). 


\section{TOPONIMI PEMUKIMAN BAGI ELITE PERDAGANGAN}

Terminologi elite perdagangan disini mengacu pada orang-orang yang memiliki akses kekuasaan dalam perdagangan di Kesultanan Banten. Jumlahnya sangat sedikit, tapi memiliki keahlian dan otoritas dalam mengatur kegiatan ekonomi. Menariknya, kaum elite ini tidak hanya berasal dari golongan bangsawan pribumi saja, tetapi dari saudagar asing atau keturunan orang asing ynang diberikan kepercayaan untuk memegang suatu jabatan tertentu karena keahliannya, seperti jabatan syahbandar yang dipegang oleh orang dari etnis Tionghoa. Berikut beberapa toponim elite perdagangan di kawasan Banten Lama:

\section{- Keraton atau Kedaton}

Keraton (berasal dari bahasa Jawa, yaitu keratuan, tempat tinggal ratu/raja) atau istana pada zaman kerajaan-kerajaan Islam di Indonesia termasuk seni bangun Islam. Keraton disebut juga dengan Kedaton (ke-datu-an, datu = ratu/raja) (J.S. Badudu \& Sutan Mohammad Zain, 1996:316, 672). Di Kawasan Banten Lama, terdapat dua keraton yang digunakan sebagai tempat tinggal sultan dan keluarganya, yaitu Keraton Surosowan dan Keraton Kaibon. Keraton adalah suatu tempat yang bukan hanya tempat kediaman raja dan keluarganya, tetapi sekaligus berfungsi sebagai pusat pemerintahan (Marwati Djoened Poesponegoro \& Nugroho Notosusanto (Ed.), 2008:201).

Kompleks Keraton Surosowan, yang dalam Sajarah Banten disebut Kedaton Pakuwon, dibangun pada masa pemerintahan Sultan Maulana Hasanuddin (1552-1570). Sedangkan tembok benteng dan gerbang yang terbuat dari bata dan batu karang dibangun oleh Maulana Yusuf (1570-1580). Sedangkan, Keraton Kaibon berasal dari kata ka-ibu-an, yaitu tempat tinggal yang diperuntukkan bagi ibunda Sultan. Kompleks ini terletak di Kampung Kroya, sekitar 500 m sebelah tenggara Keraton Surosowan dan berada di sisi jalur Jalan Serang-Banten Lama. Keraton ini bekas tempat tinggal kediaman Sultan Syafiudin, sultan Banten yang memerintah sekitar tahun 1809-1815.

\section{- Kawangsan}

Kampung ini dinamakan Kawangsan, karena dahulunya merupakan tempat tinggal Pangeran Wangsa. Berada di sebelah utara Keraton Surosowan. Namun untuk menentukan asal-usul sosok Pangeran Wangsa yang dimaksud begitu menyulitkan. Sebab, sebagian dari putra sultan maupun bangsawan keraton banyak yang menggunakan gelar wangsa. Seperti Haji Wangsaraja yaitu pembesar keraton yang ikut dalam pasukan perang melawan VOC pada tahun 1657/1658 M. Kyai Haji Wangsaraja yang bertugas untuk memelihara semangat juang dan keyakinan agama prajurit. Ada juga Wangsadiparaya sebagai gelar dari Ciipati yang diutus untuk ke Mataram.

\section{- Kapurban}

Kapurban berasal dari kata "purba" yaitu nama Pangeran Purba yang tinggal di daerah tersebut. Kampung ini terletak di sebelah utara Keraton Surosowan. Nama Pangeran Purba dalam silsilah kesultanan Banten adalah putra dari Sultan Ageng Tirtayasa Abul Fathi Abdul Fatah (Sultan VI) dan Ratu Ayu Gede. Tapi ditulis dengan nama Pangeran Arya Purbaya.

\section{- Kaloran}

Penyebutan nama kampung ini karena di wilayah ini terdapat tempat tinggal bangsawan kesultanan Banten yang bernama Pangeran Lor. Letaknya di sebelah barat laut keraton Surosowan. Merunut sejarahnya, terdapat sebutan Pangeran Lor pada dua orang yang berbeda dan zaman yang berbeda pula. Pertama, Pangeran Sabrang Lor atau Muhammad Aliuddin yang merupakan putra Sultan Maulana Hasanuddin (1552/Sultan Banten I). Kini makamnya berada di Kampung Pamarican. Kedua, salah satu putra Abulma'ali Ahmad Kenari (1640/Sultan Banten V) dengan Ratu Martakusuma (putri Pangeran Jayakarta), juga bergelar Pangeran Lor, adik dari Pangeran Surya (Sultan Ageng Tirtayasa).

\section{- Kawiragunaan}

Kawiragunaan, menunjukkan bahwa kampung tersebut merupakan tempat pemukiman Pangeran Wiraguna. Kampung ini terletak di sebelah selatan Keraton Surosowan. Pangeran Wiraguna adalah gelar yang diberikan Sultan kepada arsitek Belanda bernama Hendrik Lucaas Cardeel. Pria kelahiran Steenwijk, Belanda ini tercatat sebagai pembelot dari pemerintahan Belanda dan lebih memilih untuk bekerjasama 
dengan Kesultanan Banten. Bahkan Cardeel telah masuk Islam, oleh karenanya Belanda menjulukinya sebagai 'si pengkhianat' atau 'si murtad'.

Hendrik Lucaas Cardeel sungguh berjasa bagi pembangunan infrastruktur kota Banten. Sumbangsih pemikirannya dalam bidang arsitek diwujudkan dengan merancang pembangunan benteng kerajaan pada tahun 1680. Ia pun ikut andil dalam merancang menara Masjid Agung Banten dengan memberi sentuhan gaya Eropa berupa bentuk bangunan menara yang mirip dengan bangunan mercusuar. Bangunan Tiyamah yang berada di sebelah selatan Masjid Agung Banten menjadi mahakarya arsitektural yang tidak lepas dari kreativitas tangan seorang Cardeel.

Karena Jasa dan kesetiannya kepada Kesultanan Banten, Sultan Ageng Tirtayasa menganugerahinya gelar Pangeran Wiraguna. Setelah Kota Banten direbut Belanda pada tahun 1682, ia tetap memilih untuk mengabdi kepada raja yang baru, Sultan Haji. Lucas Cardeel mengawini salah satu mantan istri Sultan Ageng Tirtayasa dan tetap bertugas sebagai penilik pekerjaan besar (opsigter over de werkwn en het arbeijtsvolck). Hal kecil yang menarik adalah dia tidak pernah dapat membaca huruf latin, justru lebih tertarik untuk belajar aksara Jawa (Denys Lombard, 221).

Setelah Sultan Haji wafat (1687), ia diketahui menetap di Batavia sebagai penduduk biasa (burger). Ia menjadi kepala wilayah (wijkmeester Blok $M$ ) dan mengusahakan sebuah hutan kecil miliknya di pinggiran kota (Denys Lombard, 221), sebagai seorang tuan tanah dan operator mesin potong dengan kontrak harus memasok kayu kepada VOC (Alwi Shahab, 2009:137). Daerah itu yang nantinya kelak dikenal dengan nama Ragunan sekarang, yang tidak lain nama daerah tersebut berasal dari nama gelarnya sendiri, Wiraguna (Windoro Adi, 2010:440). Dewasa ini, Ragunan merupakan sebuah kelurahan di Kecamatan Pasar Minggu, Jakarta Selatan.

\section{- Kabantenan}

Kebantenan merupakan pemukiman pejabat pemerintah di lingkungan kesultanan Banten. Letak kampung ini berada di sebelah timur laut Keraton Surosowan;

\section{- Kamandalikan}

Kampung ini terletak di sebelah tenggara Keraton Surosowan. Kamandalikan yang dijadikan nama sebuah pemukiman tidak terlepas dari sosok Pangeran Arya Mandalika. Dalam Sajarah Banten pupuh XXII, tertulis bahwa Pangeran Arya Mandalika merupakan putra dari Sultan Maulana Yusuf dari selirnya. Semasa hidupnya Pangeran Arya Mandalika menjabat sebagai Panglima Perang merangkap Menteri Perlengkapan. Makam Pangeran Arya Mandalika sekarang terletak di seberang kampung Kroya.

\section{- Kademangan}

Nama kampung Kademangan berasal dari kata “demang” yaitu gelar gelar kepala daerah. Setingkat kepala distrik atau wedana pada zaman pemerintahan Hindia Belanda. Kampung Kademangan dahulu dijadikan pemukiman para demang, Toponim Kademangan pada masa Sultan Ageng Tirtayasa basis pertahanan melawan VOC. Benteng di Kademangan dan Tanahara merupakan kubu pertahanan pasukan Sultan Ageng Tirtayasa yang terkuat. Benteng di Kademangan pun akhirnya dapat dihancurkan pasukan Kapten Tack pada tanggal 2 Desember 1682. Namun belum dapat dipastikan apakah Kademangan sebagai basis pertahanan yang dimaksud sama dengan Kademangan sebagai kampung para demang.

\section{- Katengahan}

Katengahan merupakan pemukiman Arya Tengah Pangeran Jayawikarsa. Di kampung ini terdapat makam Arya Tengahyang terbuat dari batu, bata, kapur dan pasir dengan ukuran panjang $11 \mathrm{~cm}$ dan lebar $9 \mathrm{~cm}$. Menurut cerita rakyat, Arya Tengah Pangeran Jayawikarsa adalah putra Ratu Pembayun dengan Ki Gede Bagus Angke atau cucu Maulana Hasanuddin. Pada masa hidupnya, Ki Arya Tengah memiliki keris emas yang diberi nama "Ki Brogol" dan tombak yang disebut "Ki Getem" yang digunakan untuk menaklukan "Ula Lanang" (ular jantan) besar di hutan Wanasaba. Beliau pula yang membuka hutan Wanasaba.

Tugas utama Ki Arya Tengah pada masa hidupnya adalah mengumpulkan orang-orang di waktu saba besar (kumpulan negeri). Untuk meringankan tugasnya itu beliau selalu memukul gong besar yang bunyinya terdengar ke pelosok daerah Banten, sehingga orang-orang berkumpul di Paseban. Dewasa ini 
Kampung Katengahan merupakan wilayah administratif dari Desa Margasana, Kecamatan Kramatwatu, Kabupaten Serang.

\section{- Kapakihan}

Kapakihan berasal dari kata "fakih (Arab)" yaitu orang yang sangat ahli hukum Islam atau ahli fikih. Dinamakan demikian, karena di tempat ini kaum ulama hukum Islam di kesultanan Banten bertempat tinggal. Kampung Kapakihan terletak di sebelah utara Keraton Surosowan. Seorang fakih menduduki jabatan sebagai Qadhi atau Kadi, yaitu hakim agung keagamaan yang mempunyai pengaruh besar di kesultanan Banten.

Qadhi menduduki peran penting dalam dewan perwakilan kesultanan Banten ketika terjadi perwalian pasca wafatnya Maulana Yusuf. Perannya bukanlah semata-mata memberikan keputusan dalam perkara nikah, thalak, rujuk, tetapi juga dalam perkara waris dan faraidh. Bukan saja faraidh (hak waris) harta, bahkan faraidh kekuasaan pun. Karena perannya yang sebagian besar berurusan dengan masalah sosial keagamaan, dimana urusan itu sangat bersentuhan langsung dengan wong cilik, ia sangat dihormati rakyat kebanyakan.

\section{KESIMPULAN}

Seiring perkembangan jaman dan perubahan wilayah admisnitratif di kawasan Banten Lama, keberadaan dan nama-nama kampung tersebut banyak yang berubah. Namun ada juga yang masih tetap eksis sampai sekarang, seperti toponim Kasunyatan, Bugis, dan Kebalen. Jejak jalur rempah yang terkandung dalam penamaan nama tempat (toponimi) di kawasan Banten Lama menjadi simbol ataupun tanda (signs) budaya yang menghubungkan ingatan kolektif masyarakat Banten dengan kejayaan sejarah leluhurnya. Melalui toponim yang terbagi dalam tiga kategori, yaitu berdasarkan komunitas etnis, kegiatan perdagangan, dan elite perdagangan, masyarakat Banten khususnya dapat melihat dan belajar dari keunikan tinggalan budaya yang terdapat di dalamnya, baik berwujud benda (bangunan bersejarah) dan non-benda (adat istiadat, nilai, latar belakang pemberian nama) sebagai kaca benggala untuk menghadapi dinamika keidupan. 


\section{REFERENSI}

A. Daliman. (2012). Islamisasi dan Perkembangan Kerajaan-Kerajaan Islam di Indonesia. Yogyakarta: Ombak.

Desril Riva Shanti. (2010). "Bukti Hubungan Perdagangan Antara Cina dengan Banten”. Dalam Naniek Th. Harkantiningsih (Ed). Perdagangan dan Pertukaran Masa Prasejarah - Kolonial. Bandung: Balai Arkeologi Nasional \& Alqaprint.

Endang Widyastuti. (2010). "Aktivitas Perekonomian Masyarakat di Muara Ciaruteun Pada Masa Klasik”. Dalam Naniek Th. Harkantiningsih (Ed). Perdagangan dan Pertukaran Masa Prasejarah - Kolonial, Bandung: Balai Arkeologi Nasional \& Alqaprint.

Helmy Faizi Bahrul Ulumi, Jejak Warisan Budaya Jalur Rempah di Banten, disampaikan pada Seri Webinar Jalur Rempah "Warisan Budaya Jalur Rempah di Banten,” BPNB Jawa Barat, 7 November 2020.

J.S. Badudu \& Sutan Muhammad Zain. (1996). Kamus Umum Bahasa Indonesia. Jakarta: Pustaka Sinar Harapan.

J. Talens Ritual power; The installation of a king in Banten, West Java, in 1691 In: Bijdragen tot de Taal-, Land- en Volkenkunde 149 (1993), no: 2, Leiden, pp.333-355.

Lombard, Denys. (2008). Nusa Jawa: Silang Budaya, Bagian III: Warisan Kerajaan-Kerajaan Konsentris. Jakarta: Gramedia Pustaka Utama.

Marwati Djoened Poesponegoro \& Nugroho Notosusanto (Ed.). (2008). Sejarah Nasional Indonesia II: Zaman Kuno- Edisi Pemutakhiran. Jakarta: Balai Pustaka.

Sudarno. (2008). Klientalisme Politik Dan Ekonomi Pemerintahan Kesultanan Banten 1753-1777. Surakarta: UNS Press.

Tb. Hafidz Rafiuddin. (2006). Riwayat Kesulthanan Banten. Serang:

Mundardjito (Ed.). (2003). Ragam Pusaka Budaya Banten. Serang: Balai Pelestarian Peninggalan Purbakala (BP3) Serang.

Uka Tjandrasasmita. (2009). Arkeologi Islam Nusantara. Jakarta: Kepustakaan Populer Gramedia.

Van Leur, J.C. (1960 ). Indonesian Trade And Society (Essays in Asian Social and Economic History). Bandung: Sumur Bandung (formerly, N.V. Mij Vorkink-Van Hoeve, The Hague (2nd. Edition).

www.https://en.unesco.org/silkroad/content/what-are-spice-routes, diakses tanggal 16 November 2020

Yulianto Sumalyo. (2006). Arsitektur Masjid dan Monumen Sejarah Muslim. Yogyakarta: Gajah Mada University-Press.

\section{Acknowledgment}

Artikel ini merupakan hasil penelitian mandiri yang dilakukan penulis melalui riset pustaka dan studi di lapangan .

\section{Authors Bio}

Penulis Pertama (First Author) adalah staff pengajar Jurusan Pendidikan Sejarah, Fakultas Keguruan Dan Ilmu Pendidikan, Universitas Sultan Ageng Tirtayasa. Memperoleh gelar sarjana (S1) dari Fakultas Ilmu Sosial UNY dan magister (S2) dari FKIP UNS. Minat penelitiannya meliputi sejarah lokal, sejarah toponimi, historical empathy. Dapat dihubungi via email: umarhadiwibowo90@untirta.ac.id / umarSHW@gmail.com .

Prosiding ICONIC lengkapnya dapat diunduh di link berikut:

http://iconic.kebudayaan.online/wp-content/uploads/Prosiding-ICONIC2020.pdf 